\title{
Retained bones of the second twin following a cesarean section: a case report
}

This article was published in the following Dove Press journal:

International Journal of Women's Health

\section{Jude Ehiabhi Okohue (D)}

Gynescope Specialist Hospital and Department of Obstetrics and Gynaecology, Madonna University Teaching Hospital, Port Harcourt, Rivers State, Nigeria
Correspondence: Jude Ehiabhi Okohue Gynecsope Specialist Hospital, 22/24 Gynescope Drive, Port Harcourt, Rivers State, Nigeria

Tel +2348037275377

Email judosca@yahoo.com

\begin{abstract}
Twin pregnancies are increasing due to assisted reproductive techniques. Following the death of one twin in-utero, the surviving and dead twin are removed from the uterine cavity at delivery. This is a report of a 38-year-old para $0^{+3}$ woman who experienced fetal demise of one of a set of twins at 20 weeks of gestation. She had an elective cesarean section during which the dead twin was forgotten in the uterine cavity. She presented with profuse vaginal discharge that was sterile on culture. An ultrasound scan showed the presence of several echogenic substances within the endometrial cavity. These substances were hysteroscopically removed and confirmed by histology to be fetal bones. The vaginal discharge subsequently stopped. In conclusion, uterine revision should always be performed during cesarean section to prevent such an occurrence.
\end{abstract}

Keywords: cesarean, twin, fetal bones, hysteroscopy, retention

\section{Introduction}

Twin pregnancy is uncommon among humans, but the prevalence varies in different populations. The rate of twin gestation is increasing due to assisted reproductive techniques, such as in vitro fertilization (IVF). ${ }^{1}$ Fetal death after 20 weeks gestation increases the incidence of intrauterine growth restriction, preterm delivery, preeclampsia, and perinatal mortality of the surviving twin. ${ }^{2}$ Retention of a dead twin following a cesarean section is not common. A practitioner might be considered negligent if such a situation occurs, and there coul $\mathrm{d}$ be associated medico-legal consequences. This report is intended to raise awareness to this condition as well as highlight its management and prevention.

\section{Case summary}

A 38 -year-old para $0^{+3}$ woman presented with a 7-year history of infertility, and evaluation revealed uterine fibroids and bilateral tubal blockage. She had previous myomectomy followed by IVF, resulting in a twin gestation. Based on a history of three previous terminations of pregnancy and ultrasound scan findings of a short cervical length of $2.3 \mathrm{~cm}$, a prophylactic cervical cerclage using the McDonald's technique was applied. Antenatal care was continued at a different hospital. At 20 weeks gestation, a routine anomaly scan showed that one of the twins had no visible cardiac activity. A repeat ultrasound scan at 28 and 36 weeks, separately, revealed a viable cephalic presenting fetus coexisting with a nonviable fetus. An elective cesarean section was performed at the hospital where she had antenatal care at 37 weeks gestation, and a male baby weighing $2.8 \mathrm{~kg}$ with APGAR scores of 7 at 1 
min and 10 at 5 mins was delivered. Information on the handling of the uterine cavity at cesarean section was not available.

The cervical cerclage was removed. Postoperative period was complicated by repeated vaginal discharge for which no bacteria was cultured. She was discharged on the 10th postoperative day.

Ten months after the delivery, she represented to our facility with repeated vaginal discharge. On physical examination, the abdomen was normal except for the cesarean section scar. Vaginal examination showed a short cervix and copious nonfoul smelling whitish discharge from the external cervical os. Endocervical swab culture and transvaginal ultrasound scan were planned, but the patient defaulted. She returned 1 year later with persistence of vaginal discharge. A transvaginal ultrasound scan revealed a bulky anteverted uterus with a highly reflective and hyperechoic endometrial cavity. Culture of the vaginal discharge was sterile. Retention of foreign body within the uterine cavity was suspected. At hysteroscopy, various types of bony materials were present in the endometrial cavity and were removed piecemeal without difficulty and with the aid of a 5F hysteroscopic grasping forceps (Video S1; Figure 1). Following the procedure, the vaginal discharge stopped, and she remained well at 11 months of follow-up. Histology of the removed material confirmed that they were bones. The findings were communicated to the remaining members of the previous managing team as the lead physician left the institution. Table 1 shows important timelines.

\section{Discussion}

Fetal bones, which are rarely found within the uterine cavity, usually follow retained bone fragments after termination of pregnancy. However, metaplasia of mature endometrial stromal cells following chronic inflammation or trauma have been suspected to produce the same features. ${ }^{3}$

The incidence of fetal demise of one of a set of twins is approximately $3.7-6.8 \%{ }^{4}$ Intrauterine death of a twin is uncommon in the second or third trimester. The surviving twin, especially if it is a monochorionic twin, is exposed to complications, such as cerebral impairment, preterm delivery with its sequelae, and even intrauterine death. ${ }^{5}$ Mode of delivery is dependent on various factors, and intrauterine death of one of a set of twins is not an exclusive indication for cesarean section. The surviving twin in the present report did not suffer any complications. Why the remains of the dead twin were left behind during the cesarean section is not clear.

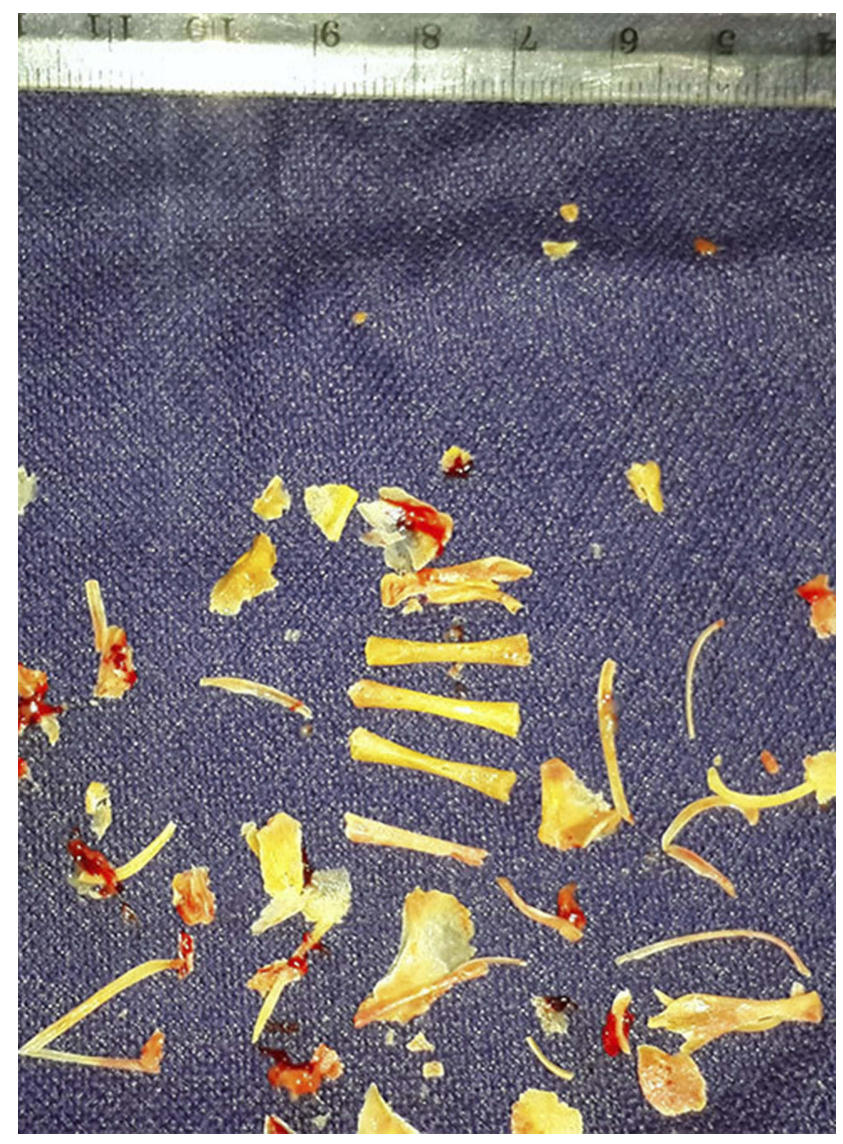

Figure I Retrieved fetal bones following hysteroscopy.

Retained fetal bones in the uterine cavity may lead to vaginal discharge, chronic pelvic pains, spontaneous passage of bone fragments during menstruation, and infertility. ${ }^{6,7}$ The patient in the present report had repeated vaginal discharge for several months. Such repeated vaginal discharge following cesarean section should be carefully evaluated to exclude retention of fetal parts.

It is important to avoid retention of fetal remains following cesarean section. Routine cleaning of the uterine cavity after delivery of the placenta at cesarean section is practiced by some. ${ }^{8}$ Such cleansing of the uterine cavity at cesarean section may help in preventing the retention of fetal parts as noted in the present report. Information on the handling of the uterine cavity at cesarean section in the present patient was not available. It is difficult to arrive at a case of medical negligence, as we did not have direct information from the managing physician. Being a resident doctor at the time, he completed his training program and left the training institution where the case was managed. It would however constitute clinical negligence if there was an omission in inspecting the uterine cavity following delivery of the baby and placenta. ${ }^{9}$ 
Table I Timeline of events

\begin{tabular}{|l|l|l|}
\hline Event & Date & Location \\
\hline Previous premarital TOP & Unsure & Different health institutions \\
Previous myomectomy & 2010 & GSH \\
Invitro fertilization/embryo transfer & 4 October 20II & GSH \\
Prophylactic cerclage & I6 December 20II & GSH June 20I2 \\
Cesarean section & I5 January 20I5 & Public health facility \\
Hysteroscopic bone retrieval & GSH \\
\hline
\end{tabular}

Abbreviations: TOP, termination of pregnancy; GSH, Gynescope Specialist Hospital.

The removal of retained fetal bones from the uterine cavity can safely be performed hysteroscopically, ${ }^{7,10}$ as noted in this report. Removal of retained bones using a curette under abdominal ultrasound scan guide after dilatation and curettage has been reported. ${ }^{11}$

In conclusion, retention of fetal bones is a rare occurrence. To our knowledge, this is the first report of retained fetal bones following a cesarean section. Vaginal discharge might be the only presenting feature, as was observed in this case. Performing a routine uterine cavity revision during cesarean section should prevent its occurrence. Hysteroscopic removal of such bones is safe and effective.

\section{Ethics and consent}

Written informed consent for publication of the clinical details and photographs was obtained from the patient for this case report and institutional approval was obtained from the research ethics committee of Gynescope Specialist Hospital to publish this case report.

\section{Disclosure}

The author declares no conflicts of interest in this work.

\section{References}

1. Okohue JE, Onuh SO, Ikimalo JI, Wada I. Patients' preference for number of embryos transferred during IVF/ICSI: a Nigerian experience. Nig J Clin Pract. 2010;13(3):294-297.
2. Chelli D, Methni A, Boudaya F, Marzouki Y, Zouaoui B, Jabnoun S Twin pregnancy with single fetal death: etiology, management and outcome. J Gynecol Obstet Biol Reprod. 2009;38(7):580-587. doi:10.1016/j.jgyn.2009.09.004

3. Grigore M, Pristavu A, Gafitanu D. Ultrasound features of osseous metaplasia of the endometrium - case series and review of the literature. Clin Imaging. 2018;52:260-263. doi:10.1016/j. clinimag.2018.08.006

4. Woo HH, Sin SY, Tang LC. Single foetal death in twin pregnancies: review of maternal and neonatal outcomes and management. Hong Kong Med J. 2000;6(3):293-300.

5. Pharoah PO, Adi Y. Consequences of in-utero death in a twin pregnancy. Lancet. 2000;355(9215):1597-1602. doi:10.1016/S0140-6736 (05)72455-7

6. Lanzarone VF, Pardey JM. Retained intrauterine fetal bone as a rare cause of secondary infertility. Aust N Z J Obstet Gynaecol. 2009;49 (6):700-701. doi:10.1111/j.1479-828X.2009.01072.x

7. Ikechebelu JI, Eleje GU, Eke NO. Hysteroscopic removal of retained intrauterine fetal bone causing chronic pelvic pain. Niger J Surg Sci. 2017;27(1):30-32. doi:10.4103/njss.njss_24_13

8. Eke AC, Denny M, Roth S, Martin D, Buras A, Woo J. Intrauterine cleaning after placental delivery at cesarean section: a randomized controlled trial. J Matern Fetal Neonatal Med. 2019;32(2):236-242. doi:10.1080/14767058.2017.1381904

9. Chukwuneke FN. Medical incidents in developing countries: a few case studies from Nigeria. Nig. J Surg Pract. 2015;18(7):20-24. doi:10.4103/1119-3077.170821

10. Gainders S, Arora P, Dhaliwal LK. Retained intrauterine bone fragments as a cause of secondary infertility in a tertiary level Indian hospital. J Hum Reprod Sci. 2018;11(3):286-290. doi:10.4103/jhrs. JHRS_33_18

11. Elford K, Claman P. Novel treatment of a patient with secondary infertility due to retained fetal bone. Fertil Steril. 2003;79(4):10281030. doi:10.1016/s0015-0282(02)04815-x

\section{Publish your work in this journal}

The International Journal of Women's Health is an international, peerreviewed open-access journal publishing original research, reports, editorials, reviews and commentaries on all aspects of women's healthcare including gynecology, obstetrics, and breast cancer. The manuscript management system is completely online and includes a very quick and fair peer-review system, which is all easy to use. Visit http://www.dovepress.com/testimonials.php to read real quotes from published authors. 